\title{
Multilevel and Spatially Heterogeneous Factors Influencing Poor Households' Income in a Frontier Minority Area in Northeast China
}

\author{
Binyan Wang $\mathbb{D}^{1},{ }^{1}$ Mark W. Rosenberg, ${ }^{2}$ Shijun Wang $\mathbb{D}^{,},{ }^{3}$ Peifeng Yang, ${ }^{4}$ and Junfeng Tian ${ }^{5}$ \\ ${ }^{1}$ School of Architecture and Urban Planning, Key Laboratory of New Technology for Construction of Cities in Mountain Area, \\ Chongqing University, Chongqing 400045, China \\ ${ }^{2}$ Department of Geography and Planning, Queen's University, Kingston, Ontario K7L3N6, Canada \\ ${ }^{3}$ School of Geographical Sciences, Northeast Normal University, Changchun, Jilin Province 130024, China \\ ${ }^{4}$ Fujian University of Technology, Fuzhou, Fujian Province 350118, China \\ ${ }^{5}$ School of Public Policy and Administration, Chongqing University, Chongqing 400044, China
}

Correspondence should be addressed to Binyan Wang; wangby@cqu.edu.cn and Shijun Wang; wangsj@nenu.edu.cn

Received 19 August 2020; Revised 2 October 2020; Accepted 4 September 2021; Published 24 September 2021

Academic Editor: Honglei Xu

Copyright (C) 2021 Binyan Wang et al. This is an open access article distributed under the Creative Commons Attribution License, which permits unrestricted use, distribution, and reproduction in any medium, provided the original work is properly cited.

Increasing the income of poor rural households is essential for the realization of China's goal of sustainable development, which entails inclusive and equitable development and reducing the developmental gap between urban and rural areas. We conducted a case study of Wangqing County, a frontier minority area in Northeast China to examine spatial patterns and income differentials among poor rural households in this area. We quantified existing associations between household-level and environmental-level characteristics and income by applying hierarchical linear models. We subsequently applied Geographically Weighted Regression to analyze the spatial heterogeneity of the environmental-level variables and develop an understanding of the interaction mechanism of influencing factors. The results revealed that the distribution of villages, where income levels were similar, showed significant spatial agglomeration characteristics. Our findings also provide empirical evidence that household- and village-level characteristics together determine the income of poor households, but that household-level characteristics determine destitution to a greater extent than environmental characteristics. More specifically, the sex, health condition, and labor capacity of the household head, household size, the dependency ratio, social welfare, and off-farm work are significantly associated with household income. At the environmental level, arable land, the distance to the county center, and the average altitude had spatially heterogeneous impacts that varied in direction and intensity. This systematic study provides a more comprehensive and integrated understanding of the factors influencing the income of poor households in a frontier minority area in Northeast China.

\section{Introduction}

Poverty is a social phenomenon that poses a challenge in countries worldwide and especially in developing countries. At the time of the founding of the People's Republic of China in 1949, China was one of the poorest countries in the world [1]. However, following the initiation of the reforms and the opening up of the economy in the late 1970s, the Chinese government has systematically planned and implemented large-scale development-oriented poverty eradication programs across the country. These programs include a series of medium- and long-term projects, notably the Seven-Year Program for Lifting 80 Million People out of Poverty (1994-2000) and the Outlines for Development-Oriented Poverty Alleviation for China's Rural Areas conducted in two phases from 2001 to 2010 and from 2011 to 2020. In recent years, rapid economic growth and urbanization have enabled China to make great strides toward reducing absolute poverty, resulting in its status as the first country in the world to achieve the United Nations goal of halving the proportion of the population living in poverty [2]. With reference to the international poverty line standard of 1.25 
US dollars per person per day, more than 700 million poor people extricated themselves from poverty between 1978 and 2015, and the number of poor in rural China was also dramatically reduced as a result of a steady increase in their income [3-5]. However, at the end of 2015, there were still 14 contiguous poor areas considered to have special difficulties, 832 impoverished counties, 128,000 registered poor villages, and 55.75 million people living in poverty in China [6]. Following the earlier rapid progress of efforts to alleviate poverty, the remaining poor are currently concentrated in remote and mountainous townships and villages. In almost half of these areas, chronic diseases are prevalent [7]. With the passage of time, the proportions of the old, sick, and disabled are increasing. This situation contrasts with the concept of sustainable development, which entails shared and inclusive development and reducing income gaps. Poverty mostly arises because of low income, and many poor households can extricate themselves from poverty by improving their income [8]. Therefore, it is important for governments, nongovernmental organizations, and multilateral institutions to know the precise reasons why longterm income remains low for households that continue to be poor, so that they can provide more targeted help to increase the income levels of poor households.

Several previous studies have explored factors that affect the income levels of poor households. Studies have mainly used one of two analytical approaches: micro-level (individual and household) and macro-level (environmental). Whereas the former focuses on the characteristics of individuals and households, the latter focuses on the characteristics of small to large geographic units, such as villages, counties, governorates, and regions $[9,10]$. Because a household is a resource-sharing unit [11], we treated households as the micro-level units in this study.

Individual and household characteristics are often explored at the micro-level to identify the causes of low income. Human capital theory posits that age, gender, education, disability, and economic activity are all related to income levels. The Sustainable Livelihoods Approach (SLA) framework, which is linked to human capital theory, emphasizes household-level assets and capabilities, such as land, labor, financial capital, productive equipment, social resources, and skills and aptitudes and be applied in an investigation of the reasons for low income [12-15]. However, the SLA considers poor people as positive beings that can secure and extend their own means of living and escape from poverty by themselves. As a result, the aged and the disabled that cannot live by physical labor are inevitably crowded out as priority targets for poverty policy from the perspective of SLA. According to spatial poverty theory proposed by Jalan and Ravallion, geographic capital is strongly linked with income in the rural areas of developing countries [16]. More recent studies have drawn attention to the linkage between income and environment at the macrolevel [17-22]. Spatial Poverty Traps (SPTs) are usually distributed in remote geographical locations, those with fragile ecological environments and poor infrastructure and public service provision, and politically disadvantaged areas. Thus, not only economic and demographic variables, but also geographic variables, such as topographical conditions, slopes, surface fragmentation, distance/travel time to public resources or services, elevation, and land use types, are closely related to income levels. A few studies have simultaneously analyzed micro-level (individual and household) and macro-level (environmental) factors affecting household income levels $[10-12,21,23]$, revealing that poor households' income levels are affected not only by variables at the household level, but also by environmental-level variables, and that environmental effects vary across different regions.

Several studies conducted on rural China have shed light on the existing state of affairs and spatial distribution of poor households' income levels and the associated driving mechanisms [24-27]. As town- and village-level data are not available, most of these studies targeted the province, city, or county levels. However, the smallest administrative unit in China, which is an administrative village, generally comprises several adjacent and unincorporated rural residential patches (also known as village settlements or Zirancun in Mandarin), in which residential houses and living facilities are built by residents [28]. Therefore, the characteristics of villages are closely associated with their inhabitants. In other words, the living conditions of residents are strongly influenced by the characteristics of village, and village characteristics are important contextual conditions. However, only a handful of studies on this topic have been carried out at multiple levels, and previous studies have not simultaneously considered household-level and environmental-level variables. By analyzing and assessing all variables at a single analytical level, most of these studies have discounted intragroup convergence effects or the differences between groups of households. Studies that have focused on the relationship between household-level variables and income tend to ignore the variances that are caused by differences in environments, which are likely to produce targeting errors. Those focusing on the relationship between environmental-level variables and income lose the household-level information. Moreover, it is important to consider the spatial heterogeneity of influencing factors, as the effects of environmental-level variables are always diversified across different areas [5, 29].

Therefore, to address the methodological and perspective limitations of earlier research, we accounted for both household-level and environment-level variables that are expected to affect the income level of a poor household. Accordingly, we first performed exploratory spatial data analysis (ESDA) to explore the spatial patterns and differential income levels of poor households across the case study area. We subsequently applied Hierarchical Linear Modeling (HLM) to examine the factors simultaneously affecting income levels at the household- and environmental levels. Lastly, we performed Geographically Weighted Regression (GWR) to identify the spatial heterogeneity of environmental-level variables to develop a better understanding of the geography of poverty. A deeper analysis enabled us to acquire a more comprehensive understanding of the complex factors that affect the income levels of poor households, and this understanding can facilitate the building of a bridge 
between the implementation of policy programs (often targeted at the environmental-level) and their expected outcomes (often targeted at the household-level). The rest of this paper is organized as follows. Section 2 introduces the study area, data sources, and research methods (ESDA, HLM, and GWR). Section 3 outlines how we achieved the three objectives of the study, described earlier, and presents a discussion of the findings of the analysis. Lastly, some conclusions are offered in Section 4.

\section{Materials and Methods}

2.1. Study Area. Wangqing County is located at $129^{\circ} 51^{\prime} \mathrm{E}-130^{\circ} 56^{\prime} \mathrm{E}$ and $43^{\circ} 06^{\prime} \mathrm{N}-44^{\circ} 03^{\prime} \mathrm{N}$ in Yanbian Korean Autonomous Prefecture, Jinlin Province, Northeast China. As one of the frontier minority areas of China, Wangqing County was listed among a set of "national impoverished counties, key counties of poverty alleviation, and development and old revolutionary areas" in 1994, 2011, and 2017, and it was categorized as one of two highly impoverished counties in Jilin Province. As shown in Figure 1, Wangqing County encompasses nine townships and 200 administrative villages, 74 of which are registered as poor villages. The county's urbanization rate reached $57.6 \%$ in 2015, which is close to the national average. But the per capita disposable incomes (PCDIs) of urban and rural residents were 18,067 yuan and 7,146 yuan, respectively, which not only indicates that there is a huge gap and significant inequality between urban and rural areas in Wangqing County, but also indicates that the PCDIs of both urban and rural residents in Wangqing County were considerably below China's national average. The total population of Wangqing County was 228,575, with $156,262(68.36 \%)$ belonging to the Han ethnic group, which is the dominant ethnic group in China, and the rest comprising ethnic minorities (e.g., Koreans, Manchu, and others), accounting for $31.64 \%$ of the county's total population. At the end of 2015, $18.25 \%$ of the rural residents were living in poverty, and the rural poverty incidence (RPI) of Wangqing County was three times higher than the mean RPI for China (5.70\%). It is noteworthy that the proportion of ethnic minorities and ethnic Han living in poverty was $17.30 \%$ and $82.70 \%$, respectively. Evidently, among ethnic minorities, the RPI, when considered along with the ethnic structure of the total population, was lower than that of the RPI of ethnic Han, which contrasts with the situation for China as a whole $[24,30]$. Therefore, Wangqing County was deemed both a representative and particular case study.

2.2. Data Sources and Processing. The household-level data used in this study was provided by the Wangqing County Office of Poverty Alleviation and Development (WOPAD), which includes basic information on 10,493 poor households obtained from 200 villages in Wangqing County in 2015. A portion of the village-level data provided by WOPAD also contained records of the socioeconomic conditions in the 200 villages, while data on village environments were obtained from the Data Center for Resources and Environmental Sciences at the Chinese Academy of Sciences (RESDC) (http://www.resdc.cn) and the Baidu Map (BM) (https://map.baidu.com/).

The household head is the key manager and decision maker within a household and has a decisive influence on the economic condition and of the household and on the livelihoods of its members. Therefore, household-level variables comprised the characteristics of the household head and the household, with the selection of variables guided mainly by the SLA framework and by those applied in empirical studies $[8-10,12,14,23,28,31]$. A detailed description of the variables is presented in Table 1. At the village level, variables were mainly determined on the basis of the theory of Two Geographical Natures [32-34]. Accordingly, we selected not only economic and demographic variables, but also geographic variables, which were related to income and were spatially heterogeneous $[5,35]$.

\subsection{Methods}

2.3.1. Exploratory Spatial Data Analysis (ESDA). We performed exploratory spatial data analysis (ESDA) to examine the spatial patterns and income differentials among poor households across the case study area using Global Moran's I and Local Indicators of Spatial Association (Lisa). The Global Moran's I was defined as follows [36]:

$$
I=\frac{N \sum_{i} \sum_{j} w_{i j}\left(x_{i}-\bar{x}\right)\left(x_{j}-\bar{x}\right)}{\left(\sum_{i} \sum_{j} w_{i j}\right) \sum_{i}\left(x_{i}-\bar{x}\right)^{2}},
$$

where $N$ is the number of village-level units, $X_{i}$ and $X_{j}$ are the variable values in villages $i$ and $j, \bar{X}$ is the average of $x$, and $W_{i j}$ is the element of a binary spatial weights matrix $W$, such that $W_{i j}=1$ if counties $i$ and $j$ share a border; otherwise, 0 . The value of global Moran's I ranged from -1 to 1 . Positive values of Moran's I indicated clusters of similar attributes, whereas negative values indicated clusters of different attributes. A value close to 0 indicates a random distribution of the attributes, that is, an absence of spatial autocorrelation $[22,25]$.

Lisa was expressed as follows [36, 37]:

$$
I_{i}=\frac{\left(x_{i}-\bar{x}\right)}{s_{x}^{2}} \sum_{j}\left[w_{i j}\left(x_{j}-\bar{x}\right)\right]
$$

where $s_{x}^{2}$ denotes the variance of variable $x$. The meanings of the other symbols corresponded to those in the Global Moran's I formula.

2.3.2. Hierarchical Linear Models. Hierarchical linear models (HLMs) are widely applied in analyses of two or more distinct hierarchical levels of data [38]. They are designed to account for the nested structure of individuals features within geographical areas, enabling the simultaneous estimation of individual and area-level effects through the modeling of complex sources of variation at different 


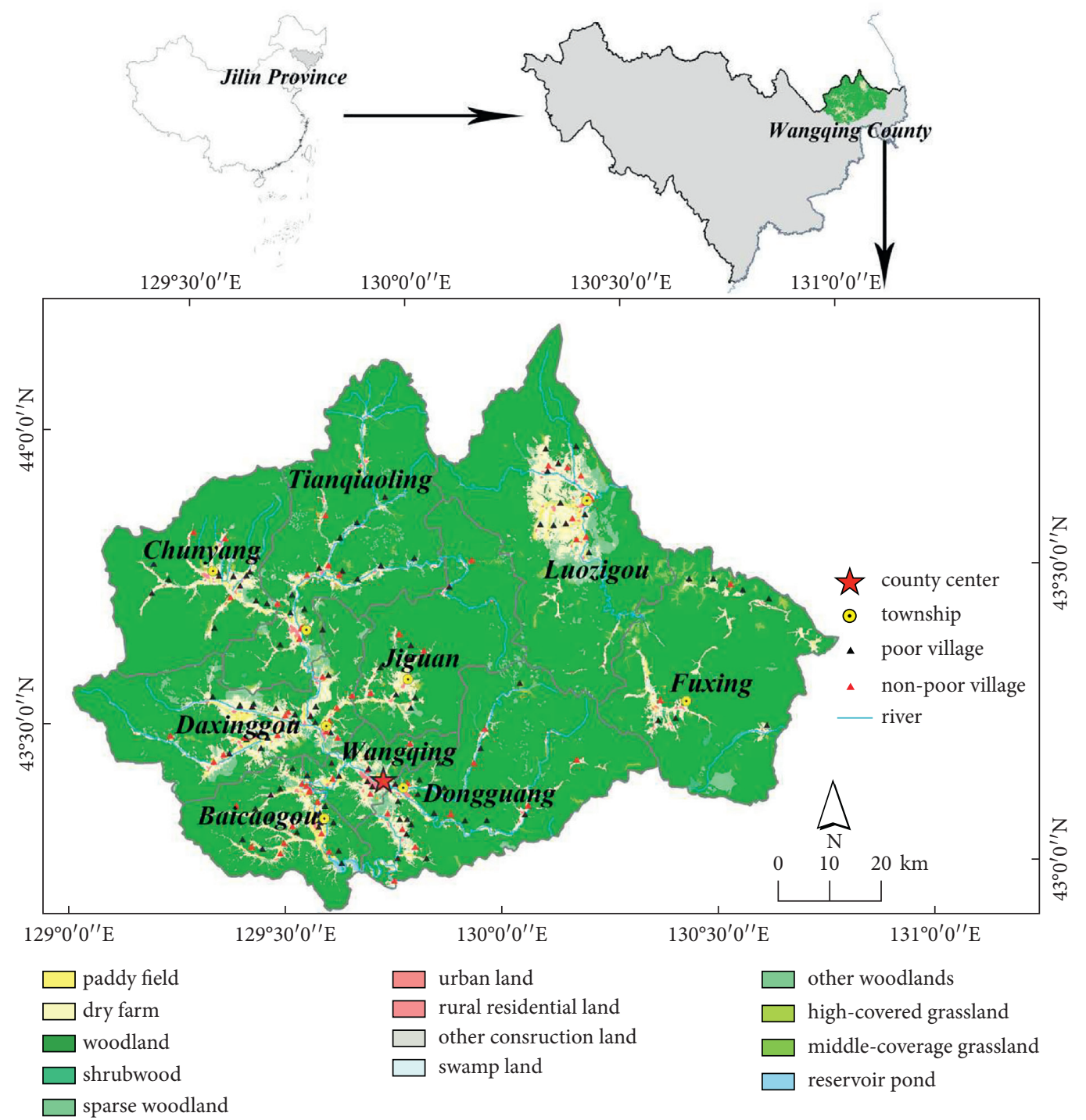

Figure 1: The location of Wangqing County.

TABLE 1: Descriptions of variables applied in the analysis.

\begin{tabular}{|c|c|}
\hline Variables & Definition (s) \\
\hline \multicolumn{2}{|l|}{ Level 1} \\
\hline Sex & Household head's sex (male/female) \\
\hline Age & Household head's age (years). \\
\hline Ethnicity & Household head's ethnicity (Han/Others) \\
\hline Education & Household head's education level (illiterate/primary school/middle school/high school/others) \\
\hline Disease & Disease status of household head (none/chronic disease/serious disease) \\
\hline Disability & Disability status of household head (none/disabled) \\
\hline Labor capacity & Labor capacity of household head (no ability/normal ability) \\
\hline Household size & Number of members. \\
\hline Dependency ratio & $\begin{array}{c}\text { Total number of members below } 16 \text { years and above } 60 \text { years as a percentage of the total number of household } \\
\text { members. }\end{array}$ \\
\hline Education burden & Number of students in school (none/one or more students) \\
\hline Social welfare & $\begin{array}{l}\text { State of household social welfare (No/dibao [receive basic living allowance] or wubao (receive the "five } \\
\text { guarantees" supporting, including food, clothing, healthcare, shelter and funeral services]) }\end{array}$ \\
\hline Off-farm work & Location of off-farm work (none/town of residence/outside town of residence) \\
\hline \multicolumn{2}{|r|}{ 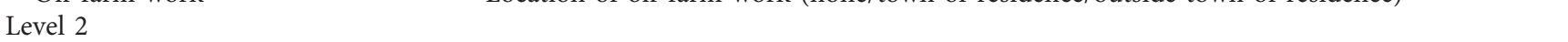 } \\
\hline Arable land & Landholding size per capita $(m \tilde{u} 0.067 \mathrm{ha})$ \\
\hline
\end{tabular}


TABLE 1: Continued.

\begin{tabular}{|c|c|}
\hline Variables & Definition (s) \\
\hline Village size & Total population of the village \\
\hline Hollowing rate & The proportion of nonpermanent residents within the total population of the village \\
\hline Number of poor & The total number of the poor \\
\hline Poverty incidence & The proportion of the poor within the total population \\
\hline Economic level & Annual per capita net income of poor households (yuan) \\
\hline Minority ratio & The proportion of the total number of the poor belonging to minority groups \\
\hline $\begin{array}{l}\text { Distance to county } \\
\text { road }\end{array}$ & Distance of a village to the nearest county road $(\mathrm{km})$ \\
\hline $\begin{array}{l}\text { Distance to township } \\
\text { road }\end{array}$ & Distance of a village to the nearest township road $(\mathrm{km})$ \\
\hline Distance to river & Distance of a village to the nearest river $(\mathrm{km})$ \\
\hline Distance to town & Distance of a village to the center of the nearest town $(\mathrm{km})$ \\
\hline $\begin{array}{l}\text { Distance to county } \\
\text { center }\end{array}$ & Time taken to reach to the center of Wangqing from a village by car (minutes, speed $=30 \mathrm{~km} / 60$ minutes) \\
\hline Average altitude & Average elevation of a village $(\mathrm{m})$ \\
\hline Topographic relief & Elevation range from the lowest point in a village to the highest $(\mathrm{m})$ \\
\hline Average slope & Average slope of a village $\left(^{\circ}\right)$ \\
\hline Average rainfall & Average annual rainfall in a village $(\mathrm{mm})$ \\
\hline Average temperature & Average annual temperature in a village $\left({ }^{\circ} \mathrm{C}\right)$ \\
\hline
\end{tabular}

hierarchical levels. Therefore, HLMs were used to analyze the influence of covariates on the annual per capita net income of poor households (PCIPs) calculated by summing four components of household income (business income, salaries, transferred earnings, and property income) and dividing this figure by household size, as well as the interactions between levels [21, 39].

We first estimated a null model (Model 1) to determine, quantitatively, whether an HLM was required and to estimate the intraclass correlation coefficient (ICC), which indicates the proportion of total variance existing among villages. The basic form of Model 1 and the definition of ICC were formulated following Raudenbush and Bryk [40]:

$$
\begin{aligned}
\text { Level }-1: Y_{i j} & =\beta_{0 j}+\varepsilon_{i j}, \\
\operatorname{Variance}\left(\varepsilon_{i j}\right) & =\delta^{2}, \\
\text { Level }-2: \beta_{0 j} & =\gamma_{00}+\mu_{0 j}, \\
\text { Variance }\left(\mu_{0 j}\right) & =\tau_{00}, \\
\operatorname{ICC} & =\frac{\tau_{00}}{\left(\tau_{00}+\delta^{2}\right)},
\end{aligned}
$$

where $Y_{i j}$ is the PCIP of a poor household $i$ living in village $j$; $\beta_{0 j}$ is the mean outcome for the $j$ th village, and $\gamma_{00}$ is the grand mean outcome for all poor households. We assumed that $\varepsilon_{i j} \sim N\left(0, \delta^{2}\right)$ for $i=1,2, \ldots, n$ poor households in village $j, j=1,2, \ldots, 200$ villages, and $\mu_{0 j} \sim N\left(0, \tau_{00}\right)$, a random error in village-level. $\delta^{2}$ and $\tau_{00}$ denote householdand village-level variance, respectively.

A random-coefficient regression model (Model 2) was subsequently estimated to investigate the coefficient of household-level variables without the village-level effects and to identify the household-level variables required to establish a two-level model for the next step. Model 2 was expressed as follows:

$$
\begin{aligned}
\text { Level - 1: } Y_{i j} & =\beta_{0 j}+\beta_{1 j} X_{i j}+\varepsilon_{i j}, \\
\text { Level - 2: } \beta_{0 j}= & \gamma_{00}+\mu_{0 j}, \\
\beta_{1 j} & =\gamma_{10}+\mu_{1 j},
\end{aligned}
$$

where $X_{i j}$ is the predictor of household $i$ in village $j, \beta_{0 j}$ and $\beta_{1 j}$ are the intercept and slope, respectively, $\gamma_{00}$ and $\gamma_{10}$ are the mean values of $\beta_{0 j}$ and $\beta_{1 j}$, respectively, and $\mu_{0 j}$ and $\mu_{1 j}$ are the random elements of $\beta_{0 j}$ and $\beta_{1 j}$, respectively, representing the variation between villages.

Lastly, a comprehensive model (Model 3), which included household- and village-level variables, was applied to investigate the extent of the variation in the slopes, which was explained using the village-level variables as predictors. The comprehensive model was expressed as follows:

$$
\begin{array}{r}
\text { Level - 1: } Y_{i j}=\beta_{0 j}+\beta_{1 j} X_{i j}+\varepsilon_{i j}, \\
\text { Level - 2: } \beta_{0 j}=\gamma_{00}+\gamma_{01} W_{j}+\mu_{0 j}, \\
\beta_{1 j}=\gamma_{10}+\gamma_{11} W_{j}+\mu_{1 j},
\end{array}
$$

where $W_{j}$ is the predictor at level 2 and $\gamma_{00}$ and $\gamma_{01}$ are the coefficients of variable $W_{j}$ for $\beta_{0 j}$ and $\beta_{k j}$, respectively, at level 2.

2.3.3. Geographically Weighted Regression (GWR). In the case of geographical phenomena, the relationship between independent and dependent variables usually varies with geographical location. In other words, spatial nonstationarity exists. At this point, the global regression model is no longer applicable [41]. To deal with the problem of spatial heterogeneity, Brunsdon et al. proposed the method of Geographically Weighted Regression (GWR) [42]. This method is used to explore spatial diversity by establishing 
different regression models for each observed location. In this study, we used GWR to detect the influencing spatial heterogeneities of environmental-level variables on the income levels of poor households. The parameters of the extended model were functions of the position variable $i$, and the formula for GWR was expressed as follows:

$$
y i=\beta_{0}\left(\mu_{i}, v_{i}\right)+\sum_{k} \beta_{k}\left(\mu_{i}, v_{i}\right) x_{i k}+\varepsilon_{i}, \quad i=1,2, \ldots, n,
$$

where $\beta_{0}\left(\mu_{i}, v_{i}\right)$ and $\varepsilon_{i}$ represent the spatial coordinates and regression residual of the $i$-th sample point, respectively, $y_{i}$ and $x_{i k}$ are the observed values of the dependent variable $y$ and independent variables $x$ at $\left(\mu_{i}, v_{i}\right), \beta_{0}\left(\mu_{i}, v_{i}\right)$ is the spatial coordinate of the $i$ th sample point, and $\beta_{k}\left(\mu_{i}, v_{i}\right)$ is the value of the continuous function $\beta_{k}(\mu, \nu)$ of the $i$ th location, and $\varepsilon_{i} \sim N\left(0, \delta^{2} I\right)$.

The study's methodological process is presented in Figure 2.

\section{Results and Discussion}

3.1. Descriptive Analysis. As shown in Table 2, 28.9\% of the 10,493 poor households in Wangqing were headed by women, and the mean age of all household heads was 65.12 years old. Most of the household heads were ethnic Han $(80.83 \%)$, and also larger than the proportion of ethnic Han in relation to the total population in Wangqing $(68.36 \%)$. Thus, the poverty incidence among ethnic minorities was lower than that for the majority population in Wangqing. Most of the household heads had low levels of education, and their physical status was poor. More than half of the household heads reported illness: $44.81 \%$ had chronic diseases, $6.00 \%$ were seriously ill, and $42.10 \%$ were disabled. For all of these reasons, the majority of household heads $(72.35 \%)$ were unable to perform routine work. The average household size was relatively small, indicating that most of the poor households consisted of just one or two persons. More precisely, $44.37 \%$ and $45.72 \%$ of households comprised one and two persons, respectively. The dependency ratio of these poor households was as high as $70.05 \%$, with $91.33 \%$ lacking an education burden. In other words, just $8.67 \%$ of the households had one or more students in their homes. According to the data collected, approximately twothirds $(66.01 \%)$ of the poor households received financial assistance through social welfare schemes from the Ministry of Civil Affairs in China. Around $88.03 \%$ of the households did not have any members engaged in off-farm work. At the village-level, all of the selected variables also varied across the villages (shown in Table 2).

\subsection{Results of the Exploratory Spatial Data Analysis (ESDA).} To determine the patterns of similarity and dissimilarity in the distribution-based clustering of the village-level annual per capita net income of poor households (VPCIPs), we examined the Global Moran's I, Local Moran's I, and Lisa cluster of the VPCIPs. Moran's I value obtained for the global spatial autocorrelation analysis was 0.1655 , indicating that there was a clustering tendency in the spatial distribution of VPCIPs. Figure 3(a) shows a positive autocorrelation for the first and third quadrants. Figure 3(b) shows the distribution of 42 out of 200 villages with significant local spatial autocorrelation $(p<0.05)$. A statistical analysis of the Lisa scores revealed that neighborhoods with significantly higher-than-average VPCIPs (high-high) were mainly clustered in Luozigou. Neighborhoods with significantly lower-than-average VPCIPs (low-low) were clustered in Jiguan and Daxinggou. The proportions of the high-high and low-low patterns in all of the villages were $5.50 \%$ and $8.00 \%$, respectively. About half of the villages with low-high patterns were also scattered in Luozigou, and the distribution of the high-low spatial patterns did not show significant regularity. The remaining villages were not spatially significant.

3.3. Results of the Hierarchical Linear Models (HLMs). Before performing a multilevel analysis, we performed a correlation analysis to examine variance inflation factors (VIFs) among all of the variables at the household-level using the SPSS program, version 23. The results showed that all of the selected household-level variables were significantly correlated with PCIPs and that the VIF of every dependent variable was well below 10. The results of Model 1 (shown in Table 3 ) reveal that both the fixed and random effects reached a significance level of $p<0.001$. The variance among villages $(1,587,194.80)$ was considerably lower than the variance among households within villages $(11,622,448.75)$. The ICC indicated that $12.02 \%$ of the total variance occurred between villages. The result of the Chisquared test for the estimated between-village variance component was highly significant, revealing significant variation among villages in relation to PCIP and also confirming that the HLMs application was both reasonable and necessary.

Table 4 shows the extent to which household-level explanatory variables were related to PCIPs after eliminating the impacts of environmental-level variables. As shown, most household-level variables were significantly associated with the PCIPs. Affected by the sex of the household head, the PCIP of a female-headed household was 540 yuan less than that of a male-headed household. The physical status of a household head was negative in relation to the PCIP. The declining health of the household head corresponded to a decrease in the PCIP. Specifically, the PCIP values for household heads with chronic and serious diseases were, respectively, 660 yuan and 867 yuan lower than that of a healthy household head. The PCIP of a disabled household head was 358 yuan lower than that of a non-disabled household head. A household's labor capacity also played an important role in the PCIP; our results indicated a higher PCIP (1,027 yuan) for a household head with normal abilities to work compared with a household head who was unable to work normally. There was also an evident relationship between the household size and PCIP. The PCIP decreased with an increase in the number of members in a household, which is in line with the findings of Cao et al., who 


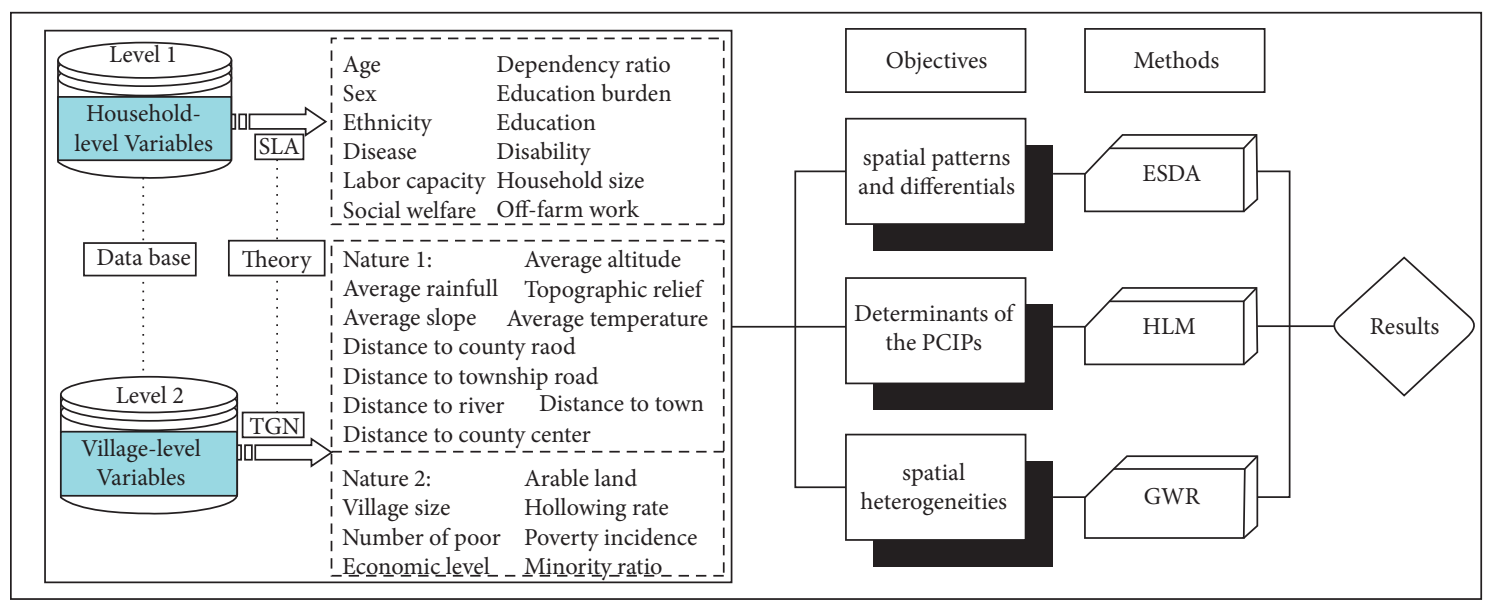

FIgUre 2: Methodological process of the study.

TABLE 2: Descriptive statistics for independent variables.

\begin{tabular}{|c|c|c|c|c|}
\hline Variables & Frequency (\%) & Mean & Sd (range) & Type \\
\hline \multicolumn{5}{|l|}{ Level $1(n=10,493)$} \\
\hline Sex (male as reference) & & 0.29 & & Dichotomous \\
\hline Male & 71.10 & & & \\
\hline Female & 28.90 & & & \\
\hline Age & & 65.12 & $12.12(8-98)$ & Continuous \\
\hline Ethnicity (Han as reference) & & 0.19 & & Dichotomous \\
\hline Han & 80.83 & & & \\
\hline Others & 19.17 & & & \\
\hline Education (illiterate as reference) & & 2.34 & & Categorical \\
\hline Illiterate & 9.98 & & & \\
\hline Primary school & 49.13 & & & \\
\hline Middle school & 37.29 & & & \\
\hline High school & 3.32 & & & \\
\hline Others & 0.28 & & & \\
\hline Disease (none as reference) & & 0.57 & & Categorical \\
\hline None & 49.19 & & & \\
\hline Chronic disease & 44.81 & & & \\
\hline Serious disease & 6.00 & & & \\
\hline Disability (none as reference) & & 0.42 & & Dichotomous \\
\hline None & 57.90 & & & \\
\hline Disabled & 42.10 & & & \\
\hline Labor capacity (no ability as reference) & & 0.28 & & Dichotomous \\
\hline No ability & 72.35 & & & \\
\hline Normal ability & 27.65 & & & \\
\hline Household size & & 1.69 & $0.74(1-6)$ & Continuous \\
\hline Dependency ratio & & 0.70 & $0.43(0-1)$ & Continuous \\
\hline Education burden (one or more students as reference) & & 0.91 & & Dichotomous \\
\hline None & 91.33 & & & \\
\hline One or more students & 8.67 & & & \\
\hline Social welfare (none as reference) & & 0.66 & & Dichotomous \\
\hline None & 33.99 & & & \\
\hline Dibao or Wubao & 66.01 & & & \\
\hline Off-farm work (none as reference) & & 0.12 & & Categorical \\
\hline None & 88.03 & & & \\
\hline Work in town & 11.24 & & & \\
\hline Work out of town & 0.73 & & & \\
\hline \multicolumn{5}{|l|}{ Level $2(n=200)$} \\
\hline Arable land & & 6.38 & $3.91(0.64-26.02)$ & Continuous \\
\hline Village size & & 546.35 & $429.81(58-2,640)$ & Continuous \\
\hline Hollowing rate & & 0.50 & $0.24(0-0.98)$ & Continuous \\
\hline
\end{tabular}


TABle 2: Continued.

\begin{tabular}{lccc}
\hline Variables & Frequency (\%) & Mean & Sd (range) \\
\hline Number of poor & 88.43 & $96.69(2-624)$ & Type \\
Poverty incidence & 0.16 & $0.09(0.01-0.57)$ & Continuous \\
Economic level & 5820 & $1,388(3,528-12,076)$ & Continuous \\
Minority ratio & 0.32 & $0.38(0-1)$ & Continuous \\
Distance to county road & 12.25 & $10.02(0.06-44.57)$ & Continuous \\
Distance to township road & 6.02 & $6.70(0.01-29.86)$ & Continuous \\
Distance to river & 3.22 & $4.39(0.03-19)$ & Continuous \\
Distance to town & 8.84 & $6.94(0.07-30.13)$ & Continuous \\
Distance to county center & 56.36 & $36.48(2.15-149.73)$ & Continuous \\
Average altitude & 531.10 & $156.48(216-852)$ & Continuous \\
Topographic relief & 439.67 & $152.86(114-1048)$ & Continuous \\
Average slope & 11.42 & $2.86(3.45-17.95)$ & Continuous \\
Average rainfall & 615.08 & $13.97(593-645)$ & Continuous \\
Average temperature & 4.79 & $1.05(1.44-6.48)$ \\
\hline
\end{tabular}

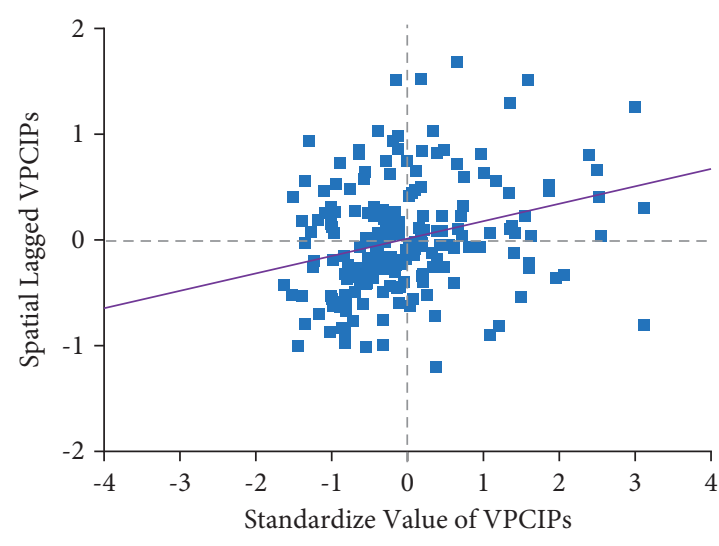

(a)

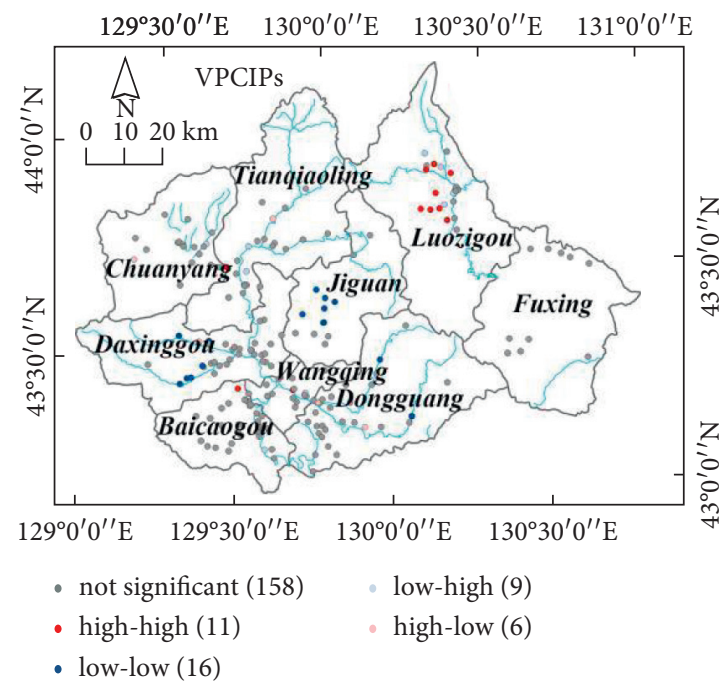

(b)

FIGURE 3: Moran scatter plot (a) and Lisa cluster map (b) of the village-level annual per capita net income of poor households (VPCIPs).

TABLE 3: Results of model 1.

\begin{tabular}{|c|c|c|c|c|c|}
\hline \multicolumn{6}{|c|}{ Fixed effects } \\
\hline Intercept & $\begin{array}{c}\text { Parameter } \\
\text { G00 }\end{array}$ & $\begin{array}{c}\text { Coefficient } \\
5,899.93\end{array}$ & $\begin{array}{l}\text { S.E. } \\
99.23\end{array}$ & $\begin{array}{c}\text { T-ratio } \\
59.46\end{array}$ & $\begin{array}{c}p \\
\leq 0.001\end{array}$ \\
\hline \multicolumn{6}{|c|}{ Random effects } \\
\hline \multirow{2}{*}{ Intercept } & Parameter & S.D. & Variance component & $x^{2}$ & $p$ \\
\hline & U0 & $1,259.84$ & $1,587,194.80$ & $1,743.42$ & $\leq 0.001$ \\
\hline Level 1 & $\mathrm{R}$ & $3,409.17$ & $11,622,448.75$ & & \\
\hline
\end{tabular}

TABLE 4: Results of model 2.

\begin{tabular}{|c|c|c|c|c|c|}
\hline & \multicolumn{3}{|c|}{ Fixed effects } & \multicolumn{2}{|c|}{ Random effects } \\
\hline & Coefficient & S.E. & T-ratio & S.D. & $x^{2}$ \\
\hline Intercept & $5453.65^{* * *}$ & 233.62 & 23.34 & 1185.51 & $98.94^{* * *}$ \\
\hline Sex (male as reference) & $-539.83^{* * *}$ & 83.18 & -6.49 & 502.31 & 5.56 \\
\hline Age & 6.15 & 4.87 & 1.26 & 25.90 & 4.05 \\
\hline Ethnicity (Han as reference) & 177.74 & 108.40 & 1.64 & 615.10 & $8.11^{* *}$ \\
\hline Education (illiterate as reference) & & & & & \\
\hline
\end{tabular}


TABLE 4: Continued.

\begin{tabular}{|c|c|c|c|c|c|}
\hline & \multicolumn{3}{|c|}{ Fixed effects } & \multicolumn{2}{|c|}{ Random effects } \\
\hline & Coefficient & S.E. & T-ratio & S.D. & $x^{2}$ \\
\hline Primary school & 83.84 & 93.77 & 0.89 & 170.68 & 0.31 \\
\hline Middle school & 114.71 & 115.07 & 1.00 & 316.84 & 1.41 \\
\hline High school & -207.07 & 173.10 & -1.20 & 542.33 & $9.97^{* *}$ \\
\hline Others & -323.67 & 590.39 & -0.55 & $2,616.12$ & 3.24 \\
\hline \multicolumn{6}{|l|}{ Disease (none as reference) } \\
\hline Chronic disease & $-660.44^{* * *}$ & 169.26 & -3.90 & $1,406.45$ & $8.08^{* *}$ \\
\hline Serious disease & $-866.95^{* * *}$ & 176.88 & -4.90 & $1,028.38$ & 2.77 \\
\hline Disability (none as reference) & $-358.18^{* *}$ & 159.00 & -2.25 & $1,221.05$ & 2.73 \\
\hline Labor capacity (no ability as reference) & $1,027.23^{* * *}$ & 127.58 & 8.05 & 955.31 & 4.53 \\
\hline Household size & $-764.28^{* * *}$ & 67.56 & -11.31 & 476.92 & 4.83 \\
\hline Dependency ratio & $-589.25^{* * *}$ & 124.84 & -4.72 & 867.33 & 2.49 \\
\hline Education burden (one or more students as reference) & 172.82 & 117.56 & 1.47 & 386.96 & 0.65 \\
\hline Social relief (none as reference) & $457.61^{* * *}$ & 113.28 & 4.04 & $1,002.61$ & 5.38 \\
\hline \multicolumn{6}{|l|}{ Off-farm work (none as reference) } \\
\hline Work in town & $1,510.34^{* * *}$ & 189.03 & 7.99 & $1,631.73$ & $30.60^{* * *}$ \\
\hline Work out of town & $2,136.57^{*}$ & $1,092.89$ & 1.96 & $6,472.54$ & $13.81^{* * *}$ \\
\hline Level 1 & & & & $3,171.38$ & \\
\hline
\end{tabular}

Note: ${ }^{*} p<0.01 ;{ }^{* *} p<0.05 ;{ }^{* * *} p<0.01$.

conducted a study of the Liangshan Yi Autonomous Prefecture in China [23] as well as those of Amara and Jemmali for Tunisia [10]. However, our findings do not support those of Chen [11] for Taiwan. The dependency ratio was also negatively associated with the PCIP. Evidently, households with a higher proportion of senile adults and children were more impoverished compared to other households. Higher dependency ratios not only indicated greater monetary expenditure on the health and health care of dependent persons, but also indicated that more time and resources were spent on caregiving. Social welfare was positively and significantly associated with PCIP: the PCIP of a household receiving social welfare was 458 yuan higher than that of a household without social welfare. Off-farm work also increased the PCIPs, in line with the research results in Vietnam and India constructed by Imai [43]. Controlling for other factors, the PCIP increased by 1,510 yuan and 2,137 yuan, respectively, for households with members who were engaged in off-farm work in town and out of town compared with that of a household with no members engaged in offfarm work. Income from agriculture is meagre in the study area. Poor households do not have a lot of land or the ability to operate large farms or ranches, and they therefore engage in off-farm work to augment their income.

The age, ethnicity, and education levels of household heads and the education burden were not significantly associated with PCIP in this area. This finding does not support those of previous studies for China as a whole [24], Korea [14], and India [21]. The reason for this difference is that, in Wangqing, more than $70 \%$ of household heads were above the age of 60 years, and most of the younger ones suffered from some form of disease. Therefore, the age of the household head was not correlated with PCIP to the same extent as in these other studies. In addition, Wangqing is located in the Yanbian
Korean Autonomous Prefecture, which is close to South Korea and has a large settled population belonging to minority groups. These groups are not treated unfairly by potential employers or customers in terms of employment and economic activities. Therefore, at the household level, the ethnicity of the household head was not related to the PCIP. Most household heads had a low education level, and just a few of the households had an education burden, so there is no significant evidence of the correlation of these factors with PCIP.

The results of the global chi-square tests for variance of household-level variables in Model 2 revealed significant variation of the following household-level variables across villages: ethnicity, high school education, chronic disease, work in town, and work out of town (in Table 4). Therefore, a full model (Model 3) was established, in which the slopes of the above five variables and intercept were treated as random and were allowed to vary across villages. Following the "t-to-enter" method [27], five variables (village size, poverty incidence, economic level, distance to county road, and distance to river) with the largest $\mathrm{t}$-values at the village-level were added to the full model (results not shown). A comparison of the original variance from Model 2 and the conditional variance from Model 3 revealed that the village-level variables had impacts at different variance levels. As shown in Table 5, after adding the village-level variables to Model 3, all of the variance components of the five household-level variables and intercepts were evidently reduced, which further confirms the significant impacts of village-level variables on the PCIPs. The variance effect of the household head's ethnicity was most affected by village-level variables (88.28\%). Moreover, the variance effects of chronic disease (55.75\%), the high school education level $(57.41 \%)$ of the household head, and off-farm work (30.66\% and $4.05 \%$, respectively, for work in town and out of town) were also clearly attributable to village-level variables. 
TABLE 5: Village-level variables explained variance components and proportions.

\begin{tabular}{lccc}
\hline & Original variance & Conditional variance & Explained variance (\%) \\
\hline Intercept & $1,405,425.01$ & $32,967.87$ & 97.65 \\
Ethnicity (Han as reference) & $383,984.23$ & $45,015.43$ & 88.28 \\
Education (illiterate as reference) & & & 57.41 \\
$\quad$ High school & $277,923.02$ & $118,367.54$ & 55.75 \\
Disease (none as reference) & & & \\
$\quad$ Chronic disease & $195,805.45$ & $86,637.87$ & 30.66 \\
Off-farm work (none as reference) & & & 4.05 \\
$\quad$ Work in town & $3,945,040.41$ & $2,735,506.87$ & $71,056,066.80$ \\
$\quad$ Work out of town & $74,052,822.40$ & & \\
\hline
\end{tabular}

3.4. Results of the Geographically Weighted Regression (GWR). In the above multilevel analysis, observations from one geographical area were assumed to be statistically independent of those in another area, so any spatial associations between geographical areas were ignored [44]. In fact, VPCIPs likely constituted a spatial phenomenon, where the VPCIPs in a region were influenced by other surrounding regions. Moreover, each region had different characteristics associated with VPCIPs. Therefore, the problem of spatial heterogeneity arose, confirming that GWR was essential.

We first constructed an OLS multivariate correlation analysis model to identify the environmental-level variables that significantly contributed to VPCIPs. After completing this step, we simply located arable land, distance to the county center, and the average altitude, which were tested and entered into the regression model. The adjusted $R^{2}$ of the OLS model was 0.147 (shown in Table 6). The VIFs were all reasonably small, so there was no strong evidence of variable redundancy. Table 6 also shows that arable land had a positive impact on VPCIPs in Wangqing, which is a common and easily understood phenomenon in most rural areas, where agriculture is the main source of income [45]. However, what was striking in our study was the positive effect of the distance to the county center on VPCIPs, indicating that a shorter distance to the county center did not make a significant positive contribution to the VPCIPs. This point is discussed further below. The average altitude also had a negative impact on VPCIPs, and this result is in line with those of studies conducted in many other parts of China and beyond [46-48]. Moran's I value in the OLS regression model was $0.082(Z=2.110, p=0.034<0.050)$, indicating that the residuals of the OLS regression model showed significant spatial autocorrelation and that a GWR model was required.

Table 7 shows that the adjusted $R^{2}$ value of the GWR model was 0.225 , which was considerably higher than the value of 0.147 determined using the OLS model. In addition, the Akaike information criterion (AIC) of the GWR model (534.628) was lower than that of the OLS model (540.443). Moran's I value for the GWR model was $0.002(Z=0.056$, $p=0.954>0.050$ ). The results of the GWR model confirmed that, compared with OLS regression model, this model, which accounted for spatial heterogeneity of variables, performed better in identifying the impacts of environmental-level factors on VPCIPs. The explanatory variable coefficients in the GWR model are presented in Figure 3.
Overall, as with the results of the OLS model, arable land and distance to the county center had positive influences on VPCIPs, whereas average altitude had a negative influence on VPCIPs. However, the impact of each explanatory variable on the VPCIPs showed spatial differences in terms of direction and intensity.

The coefficient of arable land increased moving from the county center to the periphery (Figure 4(a)). Around the area of the county center, arable land shows a weak negative influence, indicating that poor households residing in villages with less arable land had higher VPCIPs. Poor households residing in villages surrounding the county center with less arable land tend to develop some commercial agricultural activities or do some part-time work to sustain themselves as a result of low yields from limited arable land. The results of our field investigation, which were supported by the views of some government administrators, indicated that households in villages farther away from the county center with more arable land are reluctant to change their agricultural planting structure, because they can maintain their livelihoods at a subsistence level through traditional agricultural practices if they have more arable land. Compared with villages with more arable land, those with less arable land located closer to the county center tended to engage in more intensive agriculture to increase their VPCIPs. Moreover, the positive effect of arable land on VPCIPs in villages outside of the county center was stronger in the western plains than in the eastern mountainous areas.

The spatial heterogeneity of the impact of distance to the county center on VPCIPs was highly significant (Figure 4(b)). Further, this influence changed from negative to positive moving from the area around the county center to the periphery and from the south to the north. Villages distributed around the county center were more likely to be affected by their distance from the county center and evidenced closer relationships with the center. Therefore, distance to the county center evidently had a negative impact on the villages. However, the relationships between the county center and villages distributed further away weakened with the increase in distance. Villages distributed further away may develop by establishing links with other nearby counties and cities, and this is what happened in Wangqing County. On the one hand, the mountains to the east and north of Wangqing block the formation of connections between the county center and villages distributed to the east and north. On the other hand, the cities of 
TABLE 6: Estimation of regression coefficients and parameters in the OLS model.

\begin{tabular}{lccr}
\hline Variables & Standard coefficient & $\mathrm{t}$ & Sig. \\
\hline Arable land & 0.331 & 4.688 & $\leq 0.001$ \\
Distance to county center & 0.189 & 2.591 & 0.010 \\
Average altitude & -0.185 & -2.618 & 0.010 \\
Parameter & & & 1.000 \\
$R^{2}$ & 0.160 & 1.013 \\
Adjusted $R^{2}$ value & 0.147 & \\
Akaike information criterion (AIC) & 540.443 & & \\
Moran's I & 0.082 & & \\
\hline
\end{tabular}

TABLE 7: Estimation of regression coefficients and parameters in the GWR model.

\begin{tabular}{|c|c|c|c|}
\hline Variables & Minimum & Mean & Maximum \\
\hline Arable land & -0.205 & 0.309 & 0.809 \\
\hline Distance to county center & -0.982 & 0.155 & 0.501 \\
\hline Average altitude & -0.549 & -0.256 & 0.177 \\
\hline \multicolumn{4}{|l|}{ Parameter } \\
\hline$R^{2}$ & 0.309 & & \\
\hline Adjusted $R^{2}$ value & 0.225 & & \\
\hline Akaike information criterion (AIC) & 534.628 & & \\
\hline Moran's I & -0.002 & & \\
\hline
\end{tabular}

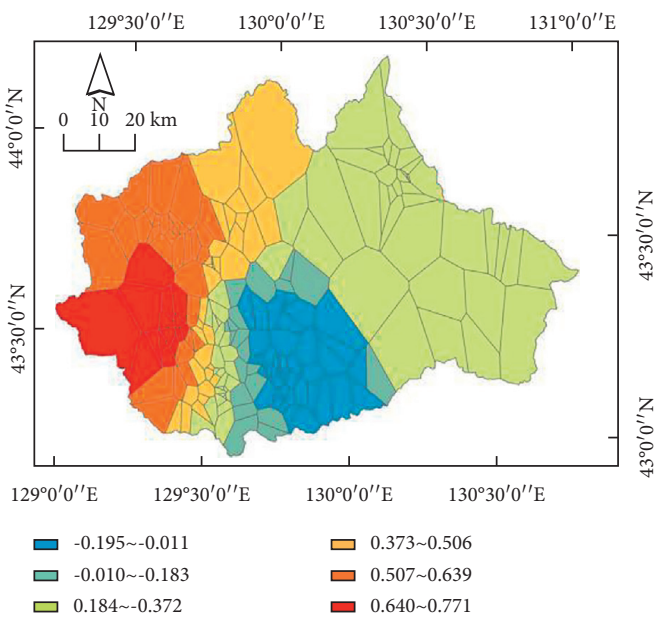

(a)

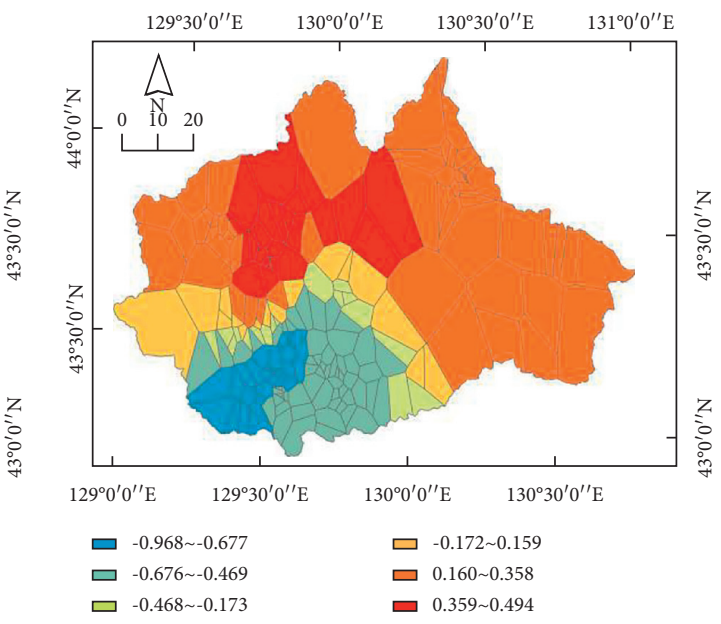

(b)

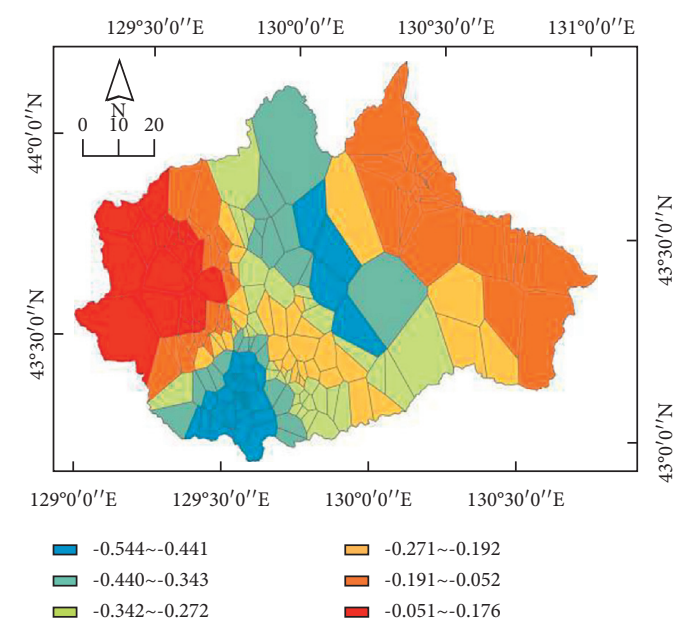

(c)

FIgURE 4: Explanatory variable coefficients of average income variables for the GWR model at the village-level. 
Mudanjiang and Ningan, which are adjacent to the northern part of Wangqing County, and the cities of Muling and Dongning, which are adjacent to the northeastern and eastern portions of Wangqing County, attract large numbers of people living in the northern and eastern parts of Wangqing, resulting in the establishment of connections. This finding is supported by the break point analysis on population and economy between Wangqing and these cities and counties [49]. Therefore, villages located east and north of Wangqing are more likely to develop closer relationships with the neighboring cities and counties given their increasing distance from the center of Wangqing County. With the increasing distance between the county center and the villages located in the east and north, the distance between these villages and the centers of neighboring counties is reduced, so it becomes easier to seek development options by connecting with neighboring counties and cities, thereby increasing household income. Consequently, the distance from the county center had a positive impact on VPCIPs in the eastern and northern parts of Wangqing County.

Overall, average altitude has a negative influence on VPCIPs (Figure 4(c)). In other words, a higher average village elevation in Wangqing corresponded to a lower VPCIP of a village. As expected, elevation had a negative effect on agricultural production, the construction of infrastructure, and access to market centers [50, 51]. Specifically, decreased average crop yields, reduced density of infrastructure, and increased costs of transportation resulted in lower income. This negative influence gradually weakened moving from the geometric center of Wangqing to the periphery and from the county center to the periphery. In addition, the western part of Wangqing County, which is at a lower average altitude than the rest of the county, is more likely to suffer from flood disasters (such as the once-in-ahundred year flooding disaster that occurred in Wangqing County on July 19-21, 2017). While the impacts of such disasters are serious, an increase in the average altitude corresponds to a relatively lower degree of disaster-induced damage. Consequently, the average altitude of the western region showed a weak positive impact.

\section{Conclusions}

Our case study revealed that, on the one hand, Wangqing demonstrates universal characteristics as a frontier minority area in China with a high overall incidence of poverty. Our findings showed that characteristic features of households in this area, most of which rely on social welfare funds and evidence a low non-agricultural participation rate, were aged heads of poor households, who were mainly male, with poor health status, a weak labor capacity, and a high dependency ratio. On the other hand, the incidence of poverty among households belonging to ethnic minorities in this area was found to be lower than that of households of Han ethnicity, with households being small and evidencing significant differences between internal units. These findings show that Wangqing has its own particular characteristics.

Our findings contribute to the literature in the following ways. First, compared with other studies, which typically only examined whether environmental-level variables affected income levels but ignored the spatial heterogeneity of environmental effects, this study extends the depth and complexity of investigations of environmental effects. Second, unlike existing studies, which typically sacrificed households' characteristics, we conducted a comprehensive analysis of household-level information. Third, our study, which focused on household- and village-scale variables, complements and provides a fine-tuned analysis not found in many existing larger-scale studies.

We can draw the following conclusions from our findings. First, the results of the ESDA showed a positive spatial correlation between the income levels of rural poor households at the village level and in the surrounding villages and units with similar income levels, revealing a spatially clustered distribution and a potential correlation between income levels and environmental factors. Second, our application of HLMs to examine the impact of household- and village-level characteristics on income levels revealed that they simultaneously determined the income levels of poor households. However, by comparing the magnitude of household- and village-level effects in the analytical process, we determined that $87.98 \%$ of the income variance occurred among households. More specifically, household characteristics relating to sex, health status (including disease and disability), labor capacity, household size, dependency ratio, social welfare, and off-farm work at the household-level significantly affected the income levels of poor households. Moreover, there were significant differences among villages relating to the household head's ethnicity, high school education level, chronic disease status, and poor households' participation in non-agricultural work. After adding village-level variables to the HLMs, the variance effect of the abovementioned indicators was explained to a different extent, and the rationality and necessity of introducing HLMs were confirmed quantitatively. Third, the results of the GWR demonstrated that the influence on income of environmental-level factors, notably the direction and intensity of arable land, the distance to the county center, and the average altitude, varied with spatial differences, which provides a more scientific and intuitive understanding of income-level differences and elucidates some of the confusion associated with the results obtained with OLS.

Following a long-standing struggle against poverty, China ultimately succeeded in forging a successful path to eliminate poverty mainly through domestic economic reforms, a development-oriented poverty reduction program, and the introduction of a system of subsistence allowances. This approach has been successful, offering valuable insights for other countries, especially developing countries, in their efforts to achieve economic and social transformation and eliminate extreme poverty. With the Belt and Road Initiative serving as a platform, China can share its experiences of successful poverty alleviation and economic development through infrastructure connectivity, facilitation of investments and trade, and cultural and people-to-people exchanges, thus advancing global poverty alleviation [52]. Although all poor households in China will come out of 
poverty through the provision of strong policy support during the targeted poverty alleviation period, their incomes are still low, and there remains a vast gap between their income and the average income of the country as a whole.

At the same time, the motivation of most poor households, characterized by high levels of vulnerability and instability, to develop is insufficient, and they therefore require continuous and sustained attention. An analysis of the impact of the characteristics of such households and of the original environmental characteristics on their income before the impacts of targeted poverty alleviation measures implemented in 2015 were strongly felt can more clearly reflect the comprehensive reasons why the income of such groups have remained low over time. These findings can motivate poor households to improve their income levels and provide an instructive reference for the governance of relative poverty and rural revitalization. After 2020, entry into a post-poverty alleviation era in a context of rural revitalization and an affluent society will provide the key for solving the problem of rural poverty, which will be transformed from absolute poverty to relative poverty, and from a focus on solving income-related poverty to solving multidimensional poverty. Therefore, the problem of poverty will become more complex, necessitating the building of a longterm mechanism of relative rural poverty governance in a context of rural revitalization and an affluent society. As a frontier minority area in China, Wangqing will continue to face the problem of relative poverty over a long period. Some people still face a high risk of returning to absolute poverty from relative poverty. Some rural areas also show obvious characteristics of recession, and the process of recession is accelerating. The contradiction in the relationship between humans and land is prominent in this region, and this relationship continues to deteriorate. Therefore, the governance of rural poverty is facing even greater challenges, and appropriate governance paths and mechanisms require further exploration.

This study had some limitations that require further discussion. Some intrinsic restrictions in the data prevented us from considering and conducting dynamic monitoring of factors affecting income levels. Moreover, the influencing mechanism of this cross-scale study along with policies and strategies for improving the income levels of poor households needs to be explored further in future studies.

\section{Data Availability}

The data are available on request.

\section{Conflicts of Interest}

There are no conflicts of interest to declare.

\section{Acknowledgments}

This work was supported by the National Natural Science Foundation of China (nos. 42101200, 42101264, and 51878084). Special thanks are due to Kim Buitenhuis for providing language help.

\section{References}

[1] L. Zhang, The Course of Poverty Reduction in China (1949-2005), China Financial \& Economic Publishing House, Beijing, China, 2007.

[2] Z. Ren, Y. Ge, J. Wang, J. Mao, and Q. Zhang, "Understanding the inconsistent relationships between socioeconomic factors and poverty incidence across contiguous poverty-stricken regions in China: multilevel modelling," Spatial Statistics, vol. 21, pp. 406-420, 2017.

[3] United Nations Development Programme (UNDP), "The Millennium development goals report 2015," Working Papers, vol. 30, no. 10, pp. 1043-1044, 2015.

[4] Y. Liu, Y. Zhou, and J. Liu, "Regional differentiation characteristics of rural poverty and targeted poverty alleviation strategy in China," Bulletin of Chinese Academy of Sciences, vol. 31, no. 3, pp. 269-278, 2016.

[5] Z. Xu, Z. Cai, S. Wu et al., "Identifying the geographic indicators of poverty using geographically weighted regression: a case study from qiandongnan miao and dong autonomous prefecture, Guizhou, China," Social Indicators Research, vol. 142, no. 3, pp. 947-970, 2019.

[6] China's State Council Information Office, China's Progress in Poverty Reduction and Human Rights, The State Council Information Office of the People's Republic of China, Beijing, China, 2016, https:/www.scio.gov.cn/ztk/dtzt/34102/35265/ 35277/Document/1494336/1494336.htm.

[7] P. Li, H. Wei, G. Wu, P. Wang, X. Tan, and J. Li, Annual Report on Poverty Reduction of China, Social Sciences Academic Press, Beijing, China, 2017.

[8] J. Zhang, F. Zuo, Y. Zhou et al., "Analyzing influencing factors of rural poverty in typical poverty areas of Hainan Province: a case study of Lingao County," Chinese Geographical Science, vol. 28, no. 6, pp. 1061-1076, 2018.

[9] D. L. Poston, J. Singelmann, C. Siordia et al., "Spatial context and poverty: area-level effects and micro-level effects on household poverty in the Texas borderland \& lower Mississippi delta: United States, 2006," Applied Spatial Analysis and Policy, vol. 3, no. 2-3, pp. 139-162, 2010.

[10] M. Amara and H. Jemmali, "Household and contextual indicators of poverty in Tunisia: a multilevel analysis," Social Indicators Research, vol. 137, no. 1, pp. 113-138, 2017.

[11] K.-M. Chen and T.-M. Wang, "Determinants of poverty status in Taiwan: a multilevel approach," Social Indicators Research, vol. 123, no. 2, pp. 371-389, 2015.

[12] K.-S. Kim, Y. Lee, and Y.-J. Lee, "A multilevel analysis of factors related to poverty in welfare states," Social Indicators Research, vol. 99, no. 3, pp. 391-404, 2010.

[13] I. Scoones, Sustainable Livelihoods and Rural Development, Practical Action Publishing, Rugby, UK, 2015.

[14] E.-Y. Park and S.-J. Nam, "Influential factors of poverty dynamics among Korean households that include the aged with disability," Applied Research in Quality of Life, vol. 13, no. 2, pp. 317-331, 2018.

[15] T. Berchoux and C. W. Hutton, "Spatial associations between household and community livelihood capitals in rural territories: an example from the Mahanadi Delta, India," Applied Geography, vol. 103, pp. 98-111, 2019.

[16] J. Jalan and M. Ravallion, "Spatial poverty traps?" Policy Research Working Paper Series 1862, The World Bank, Washington, DC, USA, 1997.

[17] K. Bird and A. Shepherd, "Livelihoods and chronic poverty in semi-arid Zimbabwe," World Development, vol. 31, no. 3, pp. 591-610, 2003. 
[18] R. Palmer-Jones and K. Sen, "It is where you are that matters: the spatial determinants of rural poverty in India," Agricultural Economics, vol. 34, no. 3, pp. 229-242, 2006.

[19] J. Szonyi, E. De Pauw, R. L. Rovere, and A. Aw-Hassan, "Mapping natural resource-based poverty, with an application to rural Syria," Food Policy, vol. 35, no. 1, pp. 41-50, 2010.

[20] S. Olivia, J. Gibson, S. Rozelle, J. Huang, and X. Deng, "Mapping poverty in rural China: how much does the environment matter?" Environment and Development Economics, vol. 16, no. 2, pp. 129-153, 2011.

[21] R. Kim, S. K. Mohanty, and S. V. Subramanian, "Multilevel geographies of poverty in India," World Development, vol. 87, pp. 349-359, 2016.

[22] Z. Ma, X. Chen, and H. Chen, "Multi-scale spatial patterns and influencing factors of rural poverty: a case study in the liupan mountain region, Gansu Province, China," Chinese Geographical Science, vol. 28, no. 2, pp. 296-312, 2018.

[23] M. Cao, D. Xu, F. Xie, E. Liu, and S. Liu, "The influence factors analysis of households' poverty vulnerability in southwest ethnic areas of China based on the hierarchical linear model: a case study of Liangshan Yi autonomous prefecture," Applied Geography, vol. 66, pp. 144-152, 2016.

[24] B. Gustafsson and D. Sai, "Temporary and persistent poverty among ethnic minorities and the majority in rural China," Review of Income and Wealth, vol. 55, pp. 588-606, 2009.

[25] Y. Liu, J. Liu, and Y. Zhou, "Spatio-temporal patterns of rural poverty in China and targeted poverty alleviation strategies," Journal of Rural Studies, vol. 52, pp. 66-75, 2017.

[26] Y. Wang, C. Liang, and J. Li, "Detecting village-level regional development differences: a GIS and HLM method," Growth and Change, vol. 50, no. 1, pp. 222-246, 2019.

[27] N. Zhang, X. Zhang, M. Lei, and Y. Yang, "Multiagent collaborative governance for targeted poverty alleviation from the perspective of stakeholders," Complexity, vol. 2020, Article ID 8276392, 21 pages, 2020.

[28] Y. Wang and H. Li, "Modeling comprehensive dispersion of the administrative villages and its association with economic poverty: a case study from poverty-stricken mountainous county, China," Social Indicators Research, vol. 133, no. 1, pp. 67-91, 2017.

[29] Y. Zhou and Y. Liu, "The geography of poverty: review and research prospects," Journal of Rural Studies, 2019, In Press.

[30] C. Gradín, "Rural poverty and ethnicity in China," Measurement of Poverty, Deprivation, and Economic Mobility, vol. 23, pp. 221-247, 2015.

[31] E. B. Barbier, "Poverty, development, and environment," Environment and Development Economics, vol. 15, no. 6, pp. 635-660, 2010.

[32] W. R. Tobler, "A computer movie simulating urban growth in the Detroit region," Economic Geography, vol. 46, pp. 234240, 1970.

[33] M. Goodchild, The Fundamental Laws of GI Science, Summer Assembly of the University Consortium for Geographic Information Science, Pacific Grove, CA, USA, 2003.

[34] P. Krugman, "First nature, second nature, and metropolitan location," Journal of Regional Science, vol. 33, no. 2, pp. 129-144, 1993.

[35] L. Wu, B. Xie, X. Xiao, B. Xue, and J. Li, "Classification method and determination of mountainous area types at township scales: a case study of yuxi city, yunnan province," Complexity, vol. 2020, Article ID 3484568, 13 pages, 2020.

[36] F. Wang, Quantitative Methods and Applications in GIS, CRC/ Taylor \& Francis, Boca Raton, FL, USA, 2016.
[37] L. Anselin, "Local indicators of spatial association-LISA," Geographical Analysis, vol. 27, no. 2, pp. 93-115, 1995.

[38] J. De Leeuw, E. Meijer, and H. Goldstein, Handbook of Multilevel Analysis, Springer, New York, NY, USA, 2008.

[39] H. Goldstein, Multilevel Statistical Models, Wiley, Chichester, UK, 4th edition, 2011.

[40] S. Raudenbush and A. Bryk, Hierarchical Linear Models: Applications and Data Analysis Methods, Sage Publications, New York, NY, USA, 2nd edition, 2002.

[41] D. P. McMillen, "Geographically weighted regression: the analysis of spatially varying relationships," American Journal of Agricultural Economics, vol. 86, no. 2, pp. 554-556, 2004.

[42] C. Brunsdon, S. Fotheringham, and M. Charlton, "Geographically weighted regression," Journal of the Royal Statistical Society: Series D (The Statistician), vol. 47, no. 3, pp. 431-443, 1998.

[43] K. S. Imai, R. Gaiha, and G. Thapa, "Does non-farm sector employment reduce rural poverty and vulnerability? Evidence from Vietnam and India," Journal of Asian Economics, vol. 36, pp. 47-61, 2015.

[44] B. Chaix, J. Merlo, S. V. Subramanian, J. Lynch, and P. Chauvin, "Comparison of a spatial perspective with the multilevel analytical approach in neighborhood studies: the case of mental and behavioral disorders due to psychoactive substance use in malmö, Sweden, 2001," American Journal of Epidemiology, vol. 162, no. 2, pp. 171-182, 2005.

[45] Y. Zhao, X. Liu, and Y. Guo, "Model analysis for spatial poverty in te poor area of Liupan Mountain in Ningxia Hui Autonomous region based on GIS," Research of Soil and Water Conservation, vol. 5, pp. 94-99, 2014.

[46] X. Chen, Z. Pei, A. L. Chen et al., "Spatial distribution patterns and influencing factors of poverty - a case study on key country from national contiguous special poverty-stricken areas in China," Procedia Environmental Sciences, vol. 26, pp. 82-90, 2015.

[47] S. Kam, M. Hossain, M. Bose, and L. Villano, "Spatial patterns of rural poverty and their relationship with welfare-influencing factors in Bangladesh," Food Policy, vol. 30, no. 5, pp. 551-567, 2005.

[48] P. O. Okwi, G. Ndeng'e, P. Kristjanson et al., "Spatial determinants of poverty in rural Kenya," Proceedings of the National Academy of Sciences, vol. 104, no. 43, pp. 16769-16774, 2007.

[49] Wangqing County People's Government, Report on the Work of Eliminating Poverty and Tackling Key Problems in Wangqing County, Wangqing County People's Government, Wangqing, China, 2018, https://122.136.128.199:8080/pub/ wq002/zt/fsafs/gztj/20180 7/t20180717_189666.html.

[50] J. L. Gallup, J. D. Sachs, and A. D. Mellinger, "Geography and economic development," International Regional Science Review, vol. 22, no. 2, pp. 179-232, 1999.

[51] T. Daimon, "The spatial dimension of welfare and poverty: lessons from a regional targeting programme in Indonesia," Asian Economic Journal, vol. 15, no. 4, pp. 345-367, 2001.

[52] X. Zhang and X. Wang, "Participating in global poverty governance: China's approach," China International Studies, vol. 04 , pp. 32-47+2, 2019. 